\section{Challenges Faced by International Medical Students Due to Changes in Canadian Entrance Exam Policy}

To the Editor,

About the Author: Pishoy is currently a final year medical student at the National University of Ireland. He is also the past Chairperson of the Association of Medical Students in Ireland and the Vice-President of the North American Irish Medical Student Association. He is also a recipient of the Alberta Innovates-Health Solutions summer Studentship and the Canadian Institutes of Health Research Summer Student Research Award.

The process of applying to postgraduate training in Canada is an arduous procedure; however, it ensures that trainees are of the highest caliber and capable of delivering an excellent standard of care. International medical school graduates must complete a postgraduate training program in order to practice as independent physicians. The application process begins with candidates undertaking the Medical Council of Canada Evaluating Examination (MCCEE), a four-hour clinical knowledge multiple choice exam that covers a wide spectrum of disciplines including medicine, surgery, obstetrics and gynaecology, psychiatry, paediatrics, and public health. Previously, this was the only examination required by most postgraduate training programs in order to apply. The MCCEE is offered in five different sittings that are evenly spaced throughout the year (Available from: http://mcc.ca/examinations/mccee/; cited 2014 Dec 1.)

The 2015 application cycle marks the first year in which most postgraduate programs will also require the completion of a second examination, the National Assessment Collaboration (NAC) OSCE. The NAC OSCE is a clinical skills exam covering the same disciplines as the MCCEE and may only be undertaken after the successful completion of the MCCEE. The NAC OSCE is offered twice a year: in September and March. Students wishing to apply to postgraduate training, which is organized by the Canadian Resident Matching Service (CaRMS), must submit their examination results for both of these exams by the November of the application year.

In order to facilitate this new examination, the Medical Council of Canada has made changes to the MCCEE eligibility, which now allows international medical students to take the exam earlier, 20 months prior to graduation (Available from: http:// mcc.ca/2013/03/mccee-eligibility-changes-for-international-medical-students/; cited 2014 Dec 1.) For prospective applicants, this requires them to take the MCCEE earlier than previous cohorts of applicants. Previously, students would undertake the MCCEE in September of the final year of medical school. In contrast, students are now recommended to undertake the MCCEE in March of their penultimate year and undertake the NAC OSCE in September of their final year (Available from: http://mcc.ca/ examinations/nac-overview/application-information/\#Timing; cited 2014 Dec 1.)

This new timeline was intended to assist international medical students in the application process, providing them the opportunity to write both the MCCEE and NAC OSCE prior to the CaRMS deadline. However, this new timeline poses several dilemmas. The first is the considerable increased workload placed on international medical students during the academic year. They are now obligated to study for the MCCEE and NAC OSCE on top of their clinical workload, often having to cover topics that they have yet to cover in their local curriculum to prepare for the examinations. As a result, the authors speculate that these changes may result in lower scores on the MCCEE, in addition to lowering their clinical performance at their home institutions.
Furthermore, the timing of examination is not student-friendly. The only NAC OSCE sitting for which student applicants are eligible is scheduled just a few weeks into the academic session (mid/late September) of their final year. We therefore recommend that the NAC OSCE be offered at more frequent intervals during the year, with at least one summer sitting. For some students, this provides the opportunity to study for, and complete, these Canadian exams during their summer break, alleviating the need to be excused from even more clinical activities.

Even in the event that a motivated student can complete all these examinations, in some provinces they are still not eligible to apply to postgraduate training programs. For example, Alberta requires applicants to graduate in the December prior to the anticipated start date of residency, automatically disqualifying most medical students (with the exception of Australian medical student who graduate in December). This is in place to ensure that graduates can participate in a mandatory induction program (Available from: http://www.aimg.ca/index. php?page $=64$; cited 2014 Dec 13.) However, by scheduling the induction program in June and requiring proof of graduation by the end of May, programs can avoid the automatic exclusion of students wishing to start training immediately after they graduate. Quebec finds itself in a similar situation, requiring that candidates successfully complete a third examination, the Medical Council of Canada Qualifying Examination Part 1, which is not possible for students to write before the CaRMS deadline for applications (Available from http://www.cmq.org/ en/ObtenirPermis/DiplomesInternationaux; cited 2014 Dec 13.) What this means for Alberta, Quebec, and other provinces with similar requirements, is that they are forgoing the opportunity to hire some of the brightest students who are taking up positions in other provinces because they do not wish to wait a year following graduation to start their postgraduate training.

While these examinations are necessary to protect medical standards and the quality of healthcare, these unnecessary hardships can be avoided by allowing international medical students to simultaneously register for both the NAC OSCE and MCCEE, without requiring them to be done in a specific order, similar to the United States Medical Licensing Examination system (Available from: http://www.usmle.org/bulletin/ eligibility/; cited 2014 Dec 1.) These proposed solutions would provide students with the opportunity to study and write these examinations without compromising their education at their local institutions.

In conclusion, the new changes in MCCEE eligibility have permitted international medical students to apply for postgraduate training in Canada within the CaRMS application timeframe. However, slightly modifying the examination timeline would improve the process further and lighten the academic hardships placed on student applicants.

Pishoy Gouda, 1,2,3 Samuel Fanous, ' John Gouda. 'National University of Ireland, Galway, Ireland. ${ }^{2}$ Association of Medical Students in Ireland

${ }^{3}$ Student Editor, IJMS.

p.gouda1@nuigalway.ie 


\section{Correspondence}

\section{Acknowledgments: None.}

Conflict of Interest Statement at Funding: The Author has no funding, financial relationships or conflicts of interest to disclose.

Author Contributions: Conception and design the work/idea, Write the manuscript, Critical revision of the manuscript, Approval of the final version: $\mathrm{PG}, \mathrm{SF}, \mathrm{JG}$.

Cite as: Couda P, Fanous S, Gouda J. Challenges Faced by International Medical Students Due to Changes in Canadian Entrance Exam Policy. Int J Med Students. 2014 Nov-2015 Mar;3(1):70-1. 